\title{
Spray/wall interaction analysis on an ECN single-hole injector at diesel-like conditions through Schlieren visualization
}

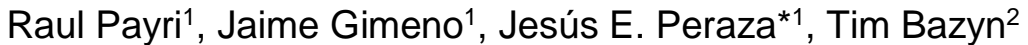 \\ ${ }^{1}$ CMT Motores Térmicos. Universitat Politècnica de València, Spain \\ ${ }^{2}$ Caterpillar Inc. Peoria, Illinois, USA \\ *Corresponding author: jepeav@mot.upv.es
}

\begin{abstract}
To continuously improve CFD models which simulate spray evolution, breakup and evaporation mechanisms, it is helpful to validate them with results obtained by experimental research. In the present study, a mono-orifice target nozzle from Engine Combustion Network, referred to as Spray D, was investigated at conditions of spray-wall interaction, which actually is a real situation in internal combustion engines that is not frequently analyzed by visualization. A Photron SA-X2 high-speed camera was employed to record the vapor phase development of the spray in an inert atmosphere using a Schlieren imaging single-pass setup. The experiments show that the spreading of the spray along the wall has a behavior fairly similar to penetration at free-jet situations, especially regarding to its susceptibility to the operating conditions and its proportionality to the square root of time once the spray reaches a steady regime interacting with the wall. Furthermore, the spray film thickness was measured at three distances from the spray-wall impact point during the injection event, thereby characterizing that parameter both spatially and temporally. The tests were carried out in a constant pressure-flow facility able to reproduce pressure and temperature conditions, similar to those seen into a diesel engine. In order to observe the behavior of the spray colliding with a wall within this test rig, a system capable to being fitted into it and to holding a fused quartz wall at different injector tip-wall distances and impingement angle configurations, was designed and employed.
\end{abstract}

\section{Introduction}

At present, the study of the spray-wall interactions into the field of transportation systems is increasingly relevant in a world aimed at reducing the displacement per cylinder of the internal combustion engines. This phenomenon plays a fundamental role in the mixing and evaporation of fuel[1]-[3], combustion behaviour and the formation of pollutant emissions[4]-[6]. Despite the growing interest around this field and the various efforts in its research [1][6], the impact of spray with a wall is a subject of difficult analysis both theoretically and experimentally due to the highly transient nature of the spray and the high spatio-temporal variability of the event. Because of this, its effects on the engine performance are not entirely known. On the one hand, the incidence and accumulation of fuel in the cylinder walls can lead to the formation of a fuel film that worsens combustion, promotes the emission of carbon monoxide and unburned hydrocarbons and involves energy losses given the increase of heat transfer [7]. On the other hand, the impact of the spray with a surface tends to improve the mixing of the fuel in the air due to both the impact and the subsequent expansion of the front of the jet. The complexity of the jet-wall impact phenomenon has to be added to the overall complexity of the injection-combustion processes, which, although they have been extensively studied in 'free jet' conditions [7]-[9] remain an active area of research.

In the literature there are a large number of experimental studies aimed at understanding physics in the spray-wall collision, in applications which are extrapolable to diesel engines. The distance from the tip of the nozzle to the surface affects the spray-wall interaction [10], since the impact conditions depend on the spray momentum and the energy exchange between the jet and the surrounding air until it hits the wall. Also, the orientation of the jet, or angle of incidence with respect to the wall also modifies the interaction mechanisms, as it changes the balance of forces during impact [11], [12]. High injection pressures increase the collision velocity, which makes the droplets smaller and improves atomization after the impact [13]. The experimental analysis of surface jet impact has been accompanied in recent years, by the development of models oriented to study both the macroscopic behavior of the jet-wall impact and the simulation of the microscopic interaction of isolated droplets [10], [12], [14]. However, there is a large number of processes that are not sufficiently known to achieve certain accurate numerical predictions, such as evaporation of the fuel film [14].

The Engine Combustion Network (ECN) is an international open group which promotes the collaboration and sharing of high quality data between scientists and institutions involved to the engines research field [15]. In order to provide a coherent and comparable database, nominally identical injectors are commonly tested at determined target conditions. This investigation attempts to conduct an experimental study to better understand the spray-wall interaction at high injection pressures under real engine conditions, employing the ECN Bosch injector referred to 
as 'Spray D'. The work characterizes the geometrical evolution of a spray after the impact with a quartz flat plate in terms of the penetration along the wall and the thickness of the spray with respect to the wall. Those parameters were obtained on the vapor phase of the spray, through the lateral view of the collision by the Schlieren optical technique. The study was conducted at several operating conditions and wall location-inclination arrangements.

\section{Material and methods}

\section{Experimental Vessel}

The experiment were performed in a high temperature and high pressure chamber which can be defined as a constant-pressure flow facility. The test section has three large windows to allow optical access to the injection process. Furthermore, the chamber is able to reproduce the in-cylinder thermo-dynamic conditions present in a Diesel engine, up to a maximum pressure of $15 \mathrm{MPa}$ and a maximum ambient temperature of $1000 \mathrm{~K}$. Although there are several test rigs over the world capable of performing analogously [8], [16], nearly quiescent and steady thermodynamic conditions can be obtained within this particular chamber. A detailed description of the vessel can be found in [7], [9], [17]. In this test rig it is possible to study the spray development either in a standard air atmosphere or with $\mathrm{O}_{2} / \mathrm{N}_{2}$ mixtures with different proportions, enabling to simulate exhaust gas recirculation conditions by decreasing the oxygen concentration of the charge. In this study, the vessel was operated at inert atmosphere conditions, filling it totally with nitrogen which flows in a closed loop to guarantee the evaporative but non-reacting desired scenario.

\section{Injection System}

The injector employed to carry out this study is referred to as Spray D \#209103 according to the Engine Combustion Network dataset. It is an axial single-hole Bosch 3-22 injector with an outlet diameter of $192 \mu \mathrm{m}$ [18], a k-factor of 1.5 whose rounded nozzle entrance and a convergent shape is oriented to avoid the cavitation phenomenon. The geometrical features of the Spray D can be found on the ECN webpage [15] and it has been hydraulically characterized in previous studies [9], [19], [20]. The injection setup consisted of a conventional Common-Rail system, which is mainly constituted by a standard rail with pressure regulator and a high pressure volumetric Bosch CP3 pump which is driven by an electric motor. The injector was kept at $363 \mathrm{~K}$ using an injector holder engineered to have a continuous ethylene glycol flow at a constant and controlled temperature running in a parallel circuit in contact with the injector during all the testing time. The injector was inserted in the test rig by this holder and connected to the common rail with a high pressure line. Moreover, the injection system is controlled by the ECU directly and all parameters are digitally inputted.

\section{Wall Supporting System}

Several 'free-jet' experiments have been carried out previously in the test rig [7]-[9], [19]. However, for this type of tests involving a wall obstructing the free path of the jet, it was necessary to design a system to reliably support the wall at determined angles and distances from the injector tip achieved with high accuracy. It was required a modification on the conventional injector protective cap (number 1 in Figure 1-left) of the test rig so that the wall supporting system could be screwed to it. Two folded sheets (2) are attached to the protective cap and also are holding two fixed ' $U$ ' shaped structures (3) which are responsible to bear the wall arrangement at its determined distance-angle configuration. Those different configuration are possible due to six pairs of exchangeable lateral frames (4). Each set of those frames is used depending on the desired distance-angle arrangement. They are screwed to a wall holder (5) which protrudes slightly on the bottom to support the JGS1 fused quartz wall (6). The support is further held in place by four claws (7) made of bent sheet that press the wall against the holder by its corners. The impact available surface of the wall is of $60 \times 100 \mathrm{~mm}^{2}$ and its thickness is $10 \mathrm{~mm}$.
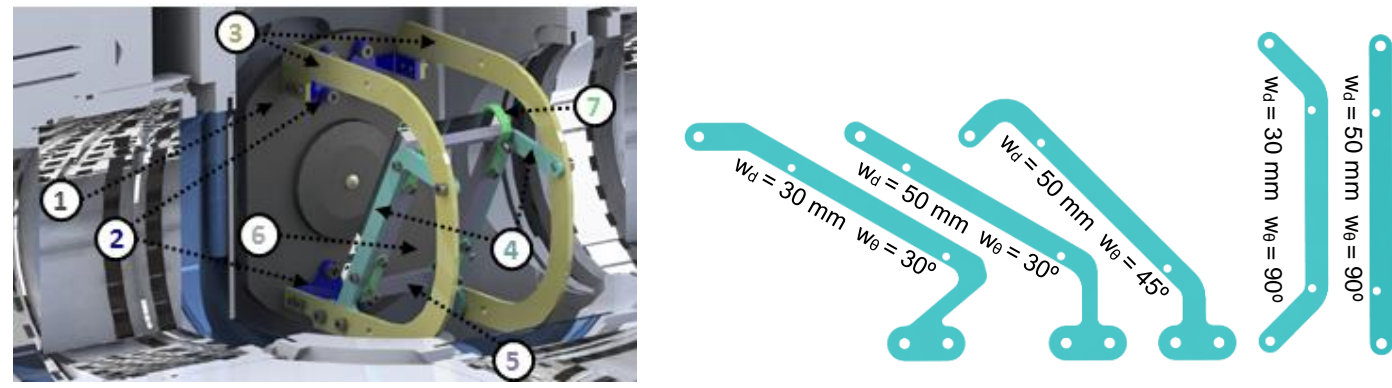

Figure 1. Right: Parts of the wall mounting system. Left: Lateral frames geometries. 


\section{Test Matrix}

Test conditions can be found summarized in Table 1. Most of them are common target conditions of the ECN [15], along with other parametric values combinations in order to embrace a wide range of test points and have a better comprehension of the parameter variation effects. Regarding to the wall position, the tests were performed with different configurations of distance from the injector tip to the plate $(\mathrm{Wd})$ and wall angle to the horizontal $(\mathrm{w} \theta)$, also detailed in Table 1. Those configurations were possible by changing the pair of frames (indicated with the number 4 in Figure 1-left), whose geometry depends on the desired configuration as shown in Figure 1-right.

\begin{tabular}{lll}
\multicolumn{3}{c}{ Table 1. Test conditions of the experiment } \\
\hline \hline Parameter & Values & Units \\
\hline \hline Fuel & Diesel & - \\
Energizing time & 2.5 & $\mathrm{~ms}$ \\
Injector tip temperature & 363 & $\mathrm{~K}$ \\
Ambient temperature $\left(T_{\text {amb }}\right)$ & $800-900$ & $\mathrm{~K}$ \\
Ambient density $\left(\rho_{\text {amb }}\right)$ & $22.8-35$ & $\mathrm{~kg} / \mathrm{m}^{3}$ \\
Injection pressure $\left(p_{\text {rail }}\right)$ & $50-100-150-200$ & $\mathrm{MPa}$ \\
Injector-wall distance $\left(w_{d}\right)$ & $30-50$ & $\mathrm{~mm}$ \\
Wall horizontal angle $\left(w_{\theta}\right)$ & $30-45^{\star}-90$ & $\mathrm{deg}\left(^{\circ}\right)$ \\
\hline
\end{tabular}

\section{Optical Setup}

In the present work, the experiments were performed using a Schlieren single-pass setup. Schlieren imaging technique consists of directing a beam of parallel light rays through a region of interest, which in this case is limited by the $128 \mathrm{~mm}$ vessel windows diameter. As these rays pass through a medium with density gradients, some of them are deflected. By collecting the resulting beam and directing it to a camera, a shadowgraph is obtained, in which the different pixel intensities are representative of different refractive indexes in the region.

A scheme of the optical setup is shown in Figure 2, where can be seen the entire light beam path from its source to the high-speed camera. The light source is a white-light $150 \mathrm{~W}$ halogen lamp with an incorporated diaphragm. The lamp is placed at the focal length of a collimating mirror that reflect the light rays making them parallel to each other. To reduce beam straightening, the incident angle of the lamp respect to the mirror was minimized. Subsequently, the beam is directed to the high pressure and high temperature vessel, where it is deflected as a result of the different densities of the interest region. After the chamber, the beam is collected by a $150 \mathrm{~mm}$ collimating lens, at whose focal distance is placed an adjustable Fourier filtering diaphragm, just before the Photron SA-X2 camera. The Fourier diaphragm is employed to filter or discard how much light may to go to the camera, controlling the sensitivity of the technique.

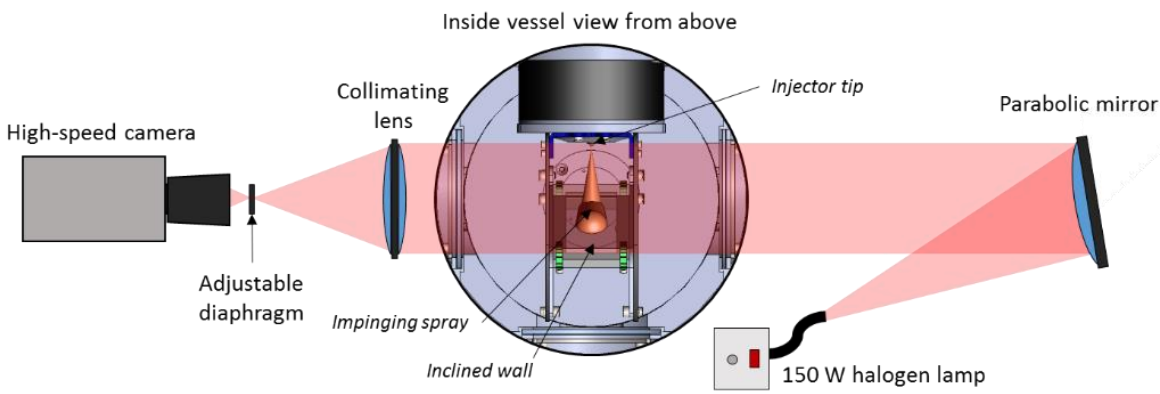

Figure 2. Scheme of the Schlieren optical setup

Image Recording and Processing

The Photron SA-X2 camera was configured to record at an acquisition speed of 40000 frames per second, which represent a time gap between images of $24 \mu \mathrm{s}$. This slight step allows detection of penetrations near to $0.4 \mathrm{~mm}$ on average, which represent good resolution to observe the spray development with time and the capability of estimate precisely the start of the injection with respect to the energizing moment given by the signal of the trigger. This recording speed could be achieved thanks to the camera's own capacity using a shutter time of $1.01 \mu$ s (time selected to provide a good compromise between sensitivity and margin of safety to avoid saturation and excessive image noise) and a spatial resolution of $512 \times 584$ pixels, which was enough to cover the spray path from the injector tip to near the wall limits without sacrificing too much camera speed. Since the pixel-per-mm relation of the images was equal to 5.88, this resolution represents an approximated image size of $87 \times 100 \mathrm{~mm}$.

This work is licensed under a Creative Commons 4.0 International License (CC BY-NC-ND 4.0). 
After recording, the information about spray evolution was extracted applying a contour-detecting processing methodology employing in-house software. First of all, it is important to highlight that the image background captured through the Schlieren technique is very irregular as seen in the leftmost image in Figure 3 , due to the heterogeneities in the temperature (i.e. density) of the nitrogen that fills the chamber, and which continuously enters and exits from it. In tests of the 'free-jet' kind, the background correction is more or less easy by taking it as the image acquired before the start of injection, and subtracting it, arithmetically, from spray images. This method is based on the assumption that, despite the background is constantly moving, this movement is slow contrasted to the spray velocities, so the background can be considered steady in the time scale of an injection event. However, the wall system inside the chamber is just after the nitrogen entry location in the chamber, and this makes the gas flow pattern more turbulent and disordered. This amplifies considerably the background noise and makes that its inhomogeneities due to the gas density gradients in the gas cannot be considered always as static between two consecutive images. The solution adopted for this issue was to average the images of all repetitions ( 8 for each condition) of the injection event, removing largely the variation of the background. Figure 3 center and right images show a comparison of an averaged image and a single shot and how the background noise affects the detected contour.
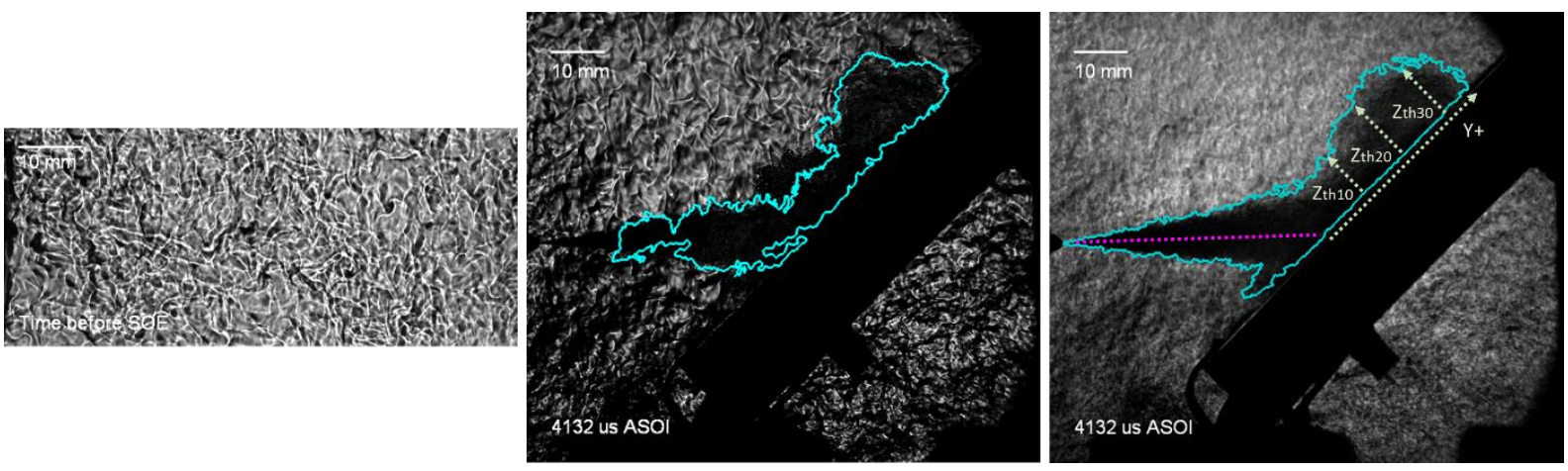

Figure 3. Comparison of backgrounds and contours at $T_{\text {amb }}=900 \mathrm{~K} ; \rho_{a m b}=35 \mathrm{~kg} / \mathrm{m}^{3} ; p_{\text {rail }}=100 \mathrm{MPa} ; w_{d}=50 \mathrm{~mm} ; w_{\theta}=45^{\circ}$. Left: Free-jet test sample before start of energizing. Center: Single-shot image of one repetition. Right: Rep-averaged image.

(Both spray contours were obtained keeping the same processing configuration)

In the following step, the repetition-averaged image is masked in the region back to the wall impact surface, in order to only get the spray development region of interest and reduce calculation time. Next, the image is inverted to have the spray as the high intensity area and the threshold is calculated as a certain percentage of the dynamic range of the image [9]. Then, some small areas which appear as result of the background noise are erased by erodingdilating filtering methods according to spray connectivity criteria. Once the spray contour has been determined, its characteristics are obtained by its analysis. In this work, the criteria followed to calculate the geometrical parameters of the spray were:

- $\quad$ Free spray penetration (S): The penetration of the spray before its impact with the wall is calculated as the position of furthest point of the contour respect to the nozzle exit.

- $\quad$ Spray spreading along the wall $\left(Y_{+}\right)$: The spray penetration along the wall is calculated as the distance between the 'collision point' and the furthest contour point in the direction of the top of the wall (considering as 'collision point' the interception between the axial spray axis and the wall plane, and not as necessarily the first point of the wall that is reached for the spray, which ideally differs of the first definition depending on the wall angle). In Figure 3 right image is shown this dimension as $Y_{+}$.

- $\quad$ Spray film thickness $\left(Z_{\text {th }}\right)$ : The thickness of the spray was measured at three consecutive places from the collision point with a distance of $10 \mathrm{~mm}$ between them. At those measuring points, the film thickness is calculated as the normal distance between the wall and the furthest contour point as seen in Figure 3.

\section{Results and discussion}

Free Penetration and Spreading onto the Plate

Figure 4 top row shows the free spray penetration and spray-wall spreading evolution with time since the start of injection changing all variables but the wall configuration, which is in this case perpendicular to the spray axis. It can be observed that the spray behavior along the wall is quite analogous to the free penetration pattern and it is affected equivalently by the parametric variations. Ambient temperature does not seems to represent a significant This work is licensed under a Creative Commons 4.0 International License (CC BY-NC-ND 4.0). 
influence on both spray advancements. On the other hand, the density has a strong effect, which seems to become higher while the spray goes over the plate. Also, the injection pressure has, as expected, a positive effect on momentum, making the spray penetrate and spread onto the wall more. However, the ASOI (after start of injection) temporal reference does not show those spray-wall spreading trends are independent of the free penetration, since the sooner the spray-wall collision, the earlier the start of the $Y_{+}$development.
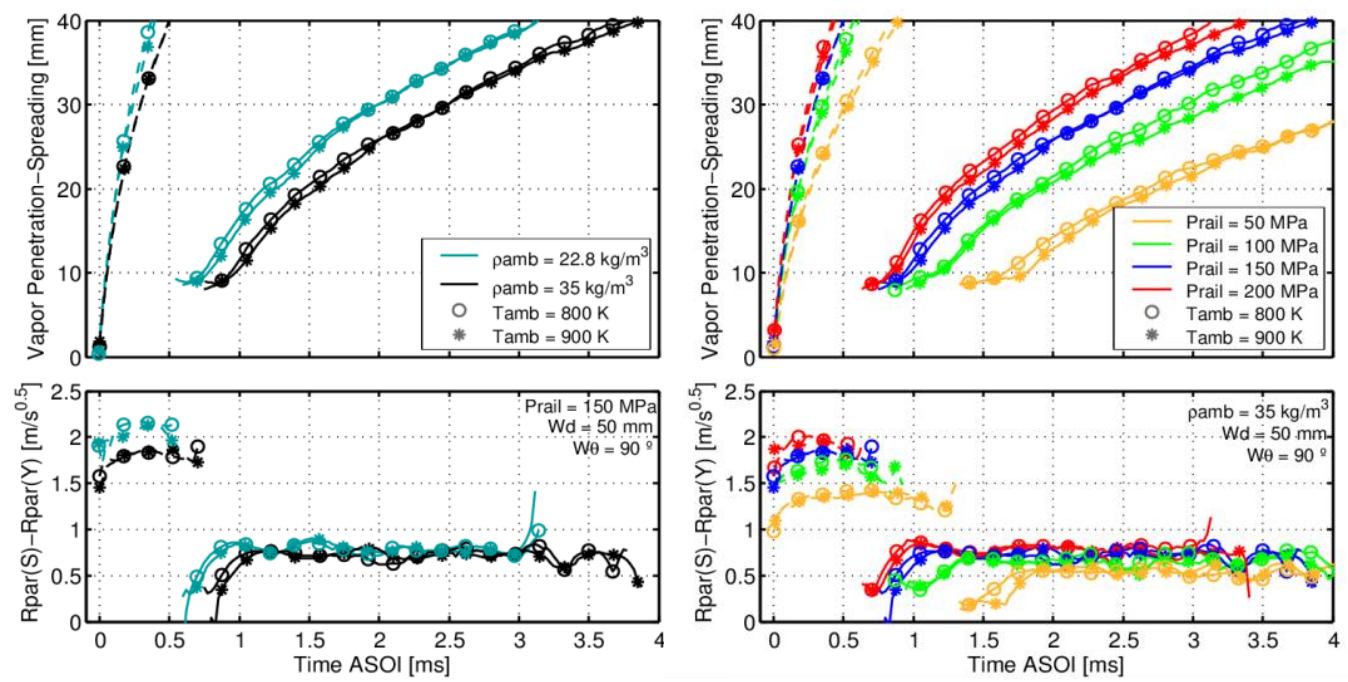

Figure 4. Free penetration (striped lines) and spreading along the wall (solid lines) together with their R-parameters at different gas and injection conditions and $w_{d}=50 \mathrm{~mm} ; w_{\theta}=90^{\circ}$. Left column: Ambient density and temperature comparison at $p_{\text {rail }}=150$ $\mathrm{MPa}$. Right column: Injection pressure and temperature contrast at $\rho_{\mathrm{amb}}=35 \mathrm{~kg} / \mathrm{m}^{3}$.

A way to express the spreading in a time-independent form and to compare its behavior with the well-known one of the free penetration, is to convert it in terms of its time squared root derivative $\partial S(t) / \partial \sqrt{ } t$, as have been made in previous works with the free penetration under the name of $R$-parameter [9], [19]. In those works, was demonstrated how, accordingly with literature, the steady spray vapor penetration of an inert spray is proportional to the time raised to the power of 0.5 , making possible to obtain a constant value referred to as $R$-parameter, independent of the time and of the penetration evolution. In Figure 4 bottom row, the squared root derivative of free penetration $\operatorname{Rpar}(S)$ and of spray-wall spreading $\operatorname{Rpar}(Y)$ are plotted. As is shown, $\operatorname{Rpar}(Y)$ also seems to reach a constant value at its stable stage. This also occurs for $\operatorname{Rpar}(S)$ although it is difficult to observe given the interruption in the evolution of the free jet by the plate. However, the trends are clear. The velocities reached by the free jet are much higher than the impinging spray velocities due to the loss of kinetic energy when hitting the wall and the spreading friction. Also, the effects of density, temperature and injection pressure seems to be the same on these timeindependent parameters for direct free jet penetration and spray-wall spreading.

On the other hand, Figure 5 shows how those same parameters are affected by the wall configuration and, again, by the density of the surroundings. As the left column plots show, the spreading onto the wall is higher for shorter distances between the injector and the plate. However, the earlier impact in the $30 \mathrm{~mm}$ case is the most important factor, so studying the $R \operatorname{par}(Y)$ is an appropriate approach to determine fundamental differences. Observing this parameter, it can be seen that the $R$-parameter is quite similar for different injector-wall distances, meaning that, even when the spreading and its velocity (the spreading curve slope) seem to differ varying wd in the left-top graph, it is a product of the different collision moments and free velocities of the spray before that instant (considering that at shorter distance from the injector tip, the spray must impact with a higher velocity). Figure 5 right column presents the effect of the wall inclination. The first remarkable thing which does not happen in the inclined plates, is that the spreading of the $90^{\circ}$ case starts in a determined value and with an inflecting behavior (also seen in Figure 4). This is because of the very width of the free jet, which makes that, at the moment of the impact of the spray tip, a short part of the wall has been already covered by the spray. This is supported by the fact that this 'initial value' given by the width seems to be larger for higher densities. This effect of the spray width is mitigated in the direction of $Y$ for the inclined plates. Furthermore, the spray-wall spreading and its $R$-parameter are strongly affected by the inclination. For the normal wall, the momentum is distributed in all directions, resulting in a spreading and an $\operatorname{Rpar}(Y)$ considerably smaller than for inclined walls. Between $30^{\circ}$ and $45^{\circ}$ the differences are not as great, because for both cases the spray momentum has as predominant direction the same as $Y_{+}$. However, observing the last and more stabilized values of $\operatorname{Rpar}(Y)$ also show a slight trend to be higher for the lower angle accordingly with the last 
deduction. It is not necessary to mention that the free-spray parameters in this cases are not affected by the wall configuration.
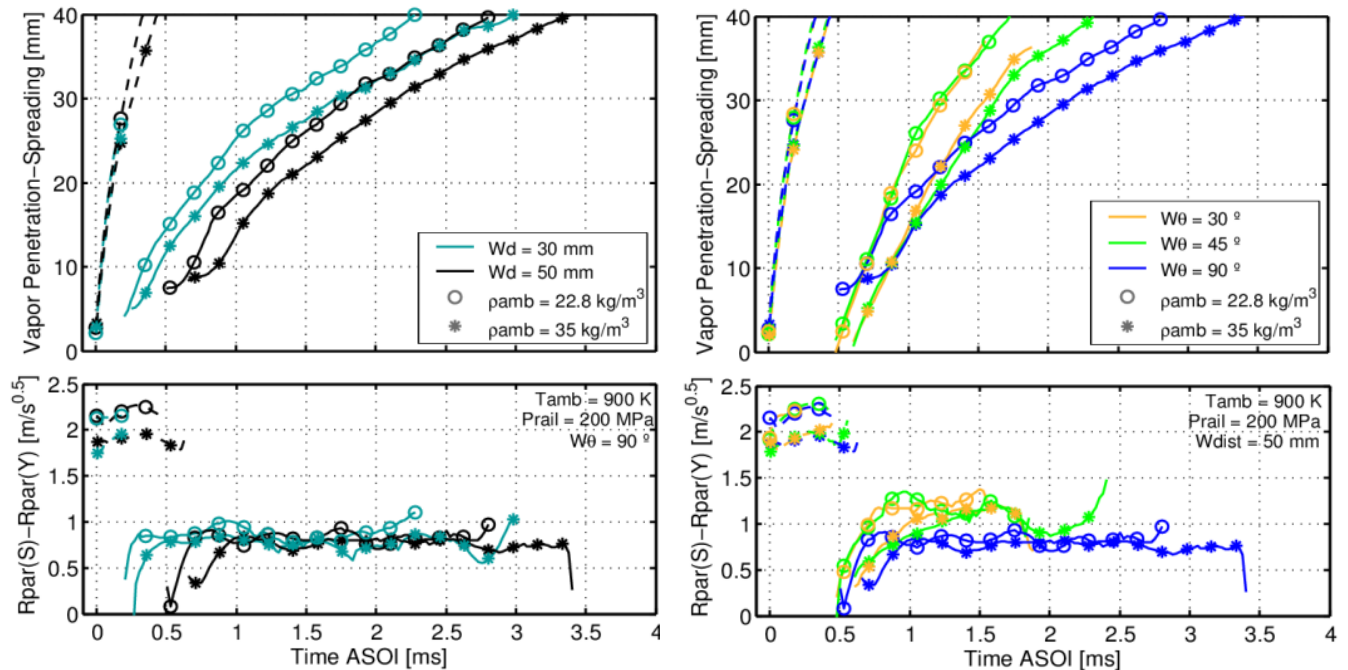

Figure 5. Free penetration (striped lines) and spreading along the wall (solid lines) together with their $R$-parameters at different wall configurations at $T_{a m b}=900 \mathrm{~K} ; p_{\text {rail }}=200 \mathrm{MPa}$. Left column: Ambient density and wall distance contrast at $w_{\theta}=90^{\circ}$. Right column: Ambient density and wall angle comparison at $\mathrm{w}_{\mathrm{d}}=50 \mathrm{~mm}$.

\section{Spray Film Thickness}

After reviewing the spreading results, the $w_{d}=30 \mathrm{~mm}-w_{\theta}=30^{\circ}$ configuration was considered by the authors as the most likely to quickly achieve steadiness in the flow onto the wall since the spray reaches the plate earlier and the transient is less abrupt when deflecting the jet at the lower angles. Figure 6 shows the spray thickness development measured at 10; 20 and $30 \mathrm{~mm}$ from the 'collision point', varying different operating conditions (in columns from left to right: density, injection pressure and gas temperature). For this wall configuration, it can be seen how the general tendency is to start growing once the spray reaches the measuring point to a maximum due to the spray front vortex, and then to slightly stabilize in a constant value. Observing the left column, it can be appreciated that, similar to the spray angle in free-jet conditions, but in a not so strong way, the density seems to widen the spray thickness as a result of the enhancement in gas entrainment into the spray. For higher densities, also the 'bump' in the thickness curves seems to last longer, however the stable final value is quite similar. With respect to the different injection pressure column of Figure 6, it shows that the thicknesses measured near the impact point, tends to the same value; but when measured further, the lower the injection pressure, the thicker the spray is. Nevertheless, in general, and similar to what happens for the spreading, the gas temperature seems to have a negligible influence on the film thickness, independently of how far it is measured. These effects on spray thickness also shown to be stronger the further they are measured, with the $Z_{\text {th10 }}$ being the distance in which the
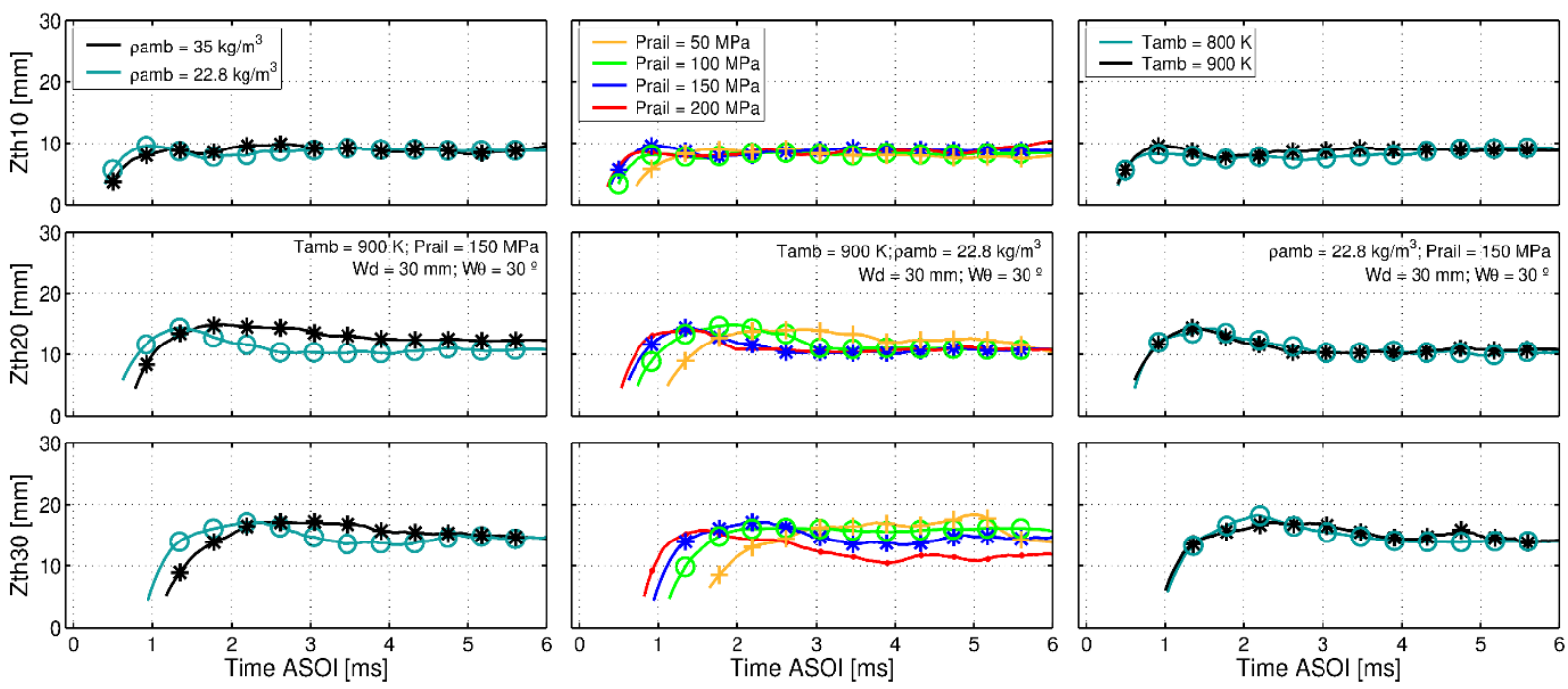

Figure 6. Spray thicknesses $Z_{\text {th } 10}, Z_{\text {th20 }}$ and $Z_{\text {th } 30}$ at a fixed wall configuration $\left(w_{d}=30 \mathrm{~mm} ; w_{\theta}=30^{\circ}\right)$. Left column: Varying ambient density. Center column: Changing injection pressure. Right column: At different ambient temperatures.

This work is licensed under a Creative Commons 4.0 International License (CC BY-NC-ND 4.0). 
operating conditions seems to affect the least. It has to be considered that before the stabilization of the impinging spray, the differences in $Z_{\text {th }}$ with the conditions, are also influenced by the difference in the moments when the spray collides with the wall and the time that takes to become steady. This effect is incremented considering the time that the spray takes to reach the measuring point. For instance, lower prail sprays not only take longer to impact with the plate, but also take longer to reach the measurement point, and this is more noticeable for the further locations as the one of $Z_{\text {th }}$.

Figure 7 shows the influence of the wall positioning on the film thickness. In the left set of plots, can be seen how despite the earlier impact at of the $30 \mathrm{~mm}$ configuration, the spray thickness takes longer to stabilize. This could be explained by the higher velocity of collision of the injection with the nearer wall, which makes the impact and spreading processes more turbulent and initially more unstable. On the other hand, Figure 7 right column shows different angle configurations, where it can be seen how the steady value of the thickness is pretty similar for all of them, but it is reached differently by each. The perpendicular wall case, exhibits a slow stabilization while the inclined ones seems to be significantly faster to stabilize. Even between $30^{\circ}$ and $45^{\circ}$, it can be noted how the $30^{\circ}$ case stabilizes faster, probably because the deviation of the flow is less and causes the least disturbances in the spray evolution. The greater the angle, the more transitory the behavior of the spray-wall impact is.
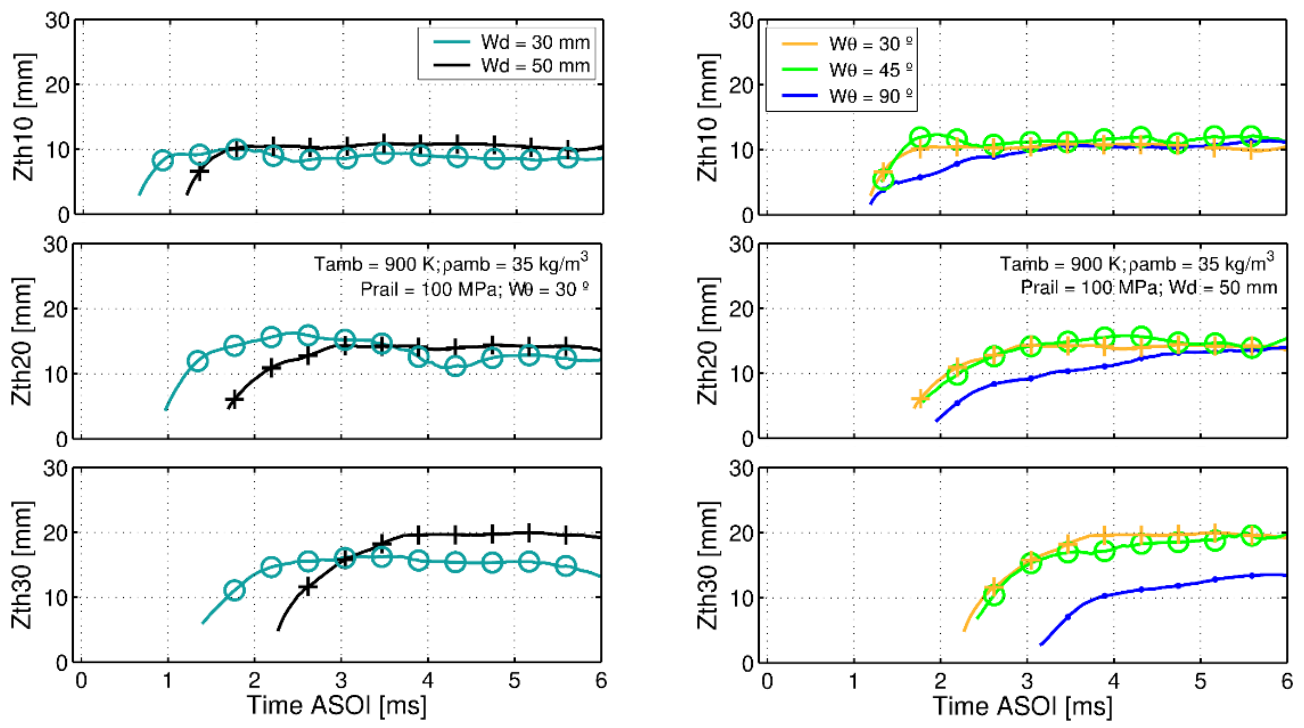

Figure 7. Spray thicknesses $Z_{\text {th10 }}, Z_{\text {th20 }}$ and $Z_{\text {th30 }}$ at a determined ambient and injection condition $\left(T_{\text {amb }}=900 \mathrm{~K} ; \rho_{\text {amb }}=35 \mathrm{~kg} / \mathrm{m}^{3}\right.$; $p_{\text {rail }}=100 \mathrm{MPa}$ ). Left column: Changing injector-wall distance. Right column: Varying wall angle.

\section{Conclusions}

The effects of ambient and injection conditions and wall positioning were analysed. Results show that the spreading along the wall and the 'free' penetration are both affected similarly by gas density, temperature and injection pressure. Since a unique time start reference does not define the wall interaction phenomenon as easily and accurately as the ASOI for the free-jet stage, those parametric behaviors were also studied employing the definition of $R$-parameter. The wall spreading is also strongly affected by the wall angle, due to change in the spray momentum deviation. Injector-wall distance seems not to have an important influence on spreading. The thickness of the spray along the wall was measured at different locations and inclinations, determining that, broadly speaking, it can be described by an initial thick region followed by stabilization at a thinner value. This steady value is higher at further measuring distances due to its progressive expansion. This metric was studied under several parametric changes, determining how it is affected by different variables.

Although a flat wall is a simplified geometry compared with a typical piston-bowl into a reciprocating engine, the possibility of making these kinds of experiments at real-engine conditions is an opportunity to study a fundamental factor on combustion such as the mixing process, in terms of the vapor spray geometry; considering the existing phenomenon of spray-wall interaction. This study represents a huge potential to improve the understanding, not only experimentally through big test rigs, but numerically also as a next step, of the processes that concern the diesel engines research.

\section{Acknowledgements}

The authors would like to thank Caterpillar Inc. for their cooperation during the project, as well as the support provided by the "Ministerio de Economía y Competitividad" of the Spanish Government in the frame of the project This work is licensed under a Creative Commons 4.0 International License (CC BY-NC-ND 4.0). 
TRA2015-67679-c2-1-R. Furthermore, the collaboration of Alberto Viera ${ }^{1}$ and Borja Hurtado ${ }^{1}$ in the measurements and setup of the experiment is thanked.

\section{Nomenclature}

ASOI after start of injection

CFD Computational Fluid Dynamics

ECN Engine Combustion Network

Prail injection pressure

$R \operatorname{Rar}(X)$ squared root of ' $X$ respect of time $\left[\mathrm{m} \mathrm{s}^{-0.5}\right]$

$S \quad$ free-jet penetration [mm]

Tamb ambient temperature $[\mathrm{K}]$ $\mathrm{t} \quad$ time

$\mathrm{W}_{\mathrm{d}} \quad$ injector tip-wall axial distance [mm]

$W_{\theta} \quad$ wall angle respect to the injector axis [deg]

$Y_{+} \quad$ spray spreading along the wall [mm]

$Z_{\text {th }} \quad$ spray thickness respect to the plate $[\mathrm{mm}]$

Pamb ambient density $\left[\mathrm{kg} \mathrm{m}^{-3}\right]$

\section{References}

[1] G. E. Cossali, A. Coghe, and G. Brunello, "Effect of Spray-Wall Interaction on Air Entrainment in a Transient Diesel Spray," in SAE Technical Paper, 1993.

[2] K. Li, P. Dong, T. Matsuo, B. Shi, Y. Ogata, and K. Nishida, "Characteristics of Diesel Spray Flame under Flat Wall Impinging Condition --LAS, $\mathrm{OH}^{*}$ Chemiluminescence and Two Color Pyrometry Results," in SAE Technical Paper, 2014.

[3] J. Senda, Y. Tanabe, H. Fujimoto, and Y. Fukami, "Vizualization of Evaporative Diesel Spray Impinging Upon Wall Surface by Exciplex Fluorescence Method," in SAE Technical Paper, 1992.

[4] A. Mohammadi, Y. Kidoguchi, and K. Miwa, "Effect of Injection Parameters and Wall-Impingement on Atomization and Gas Entrainment Processes in Diesel Sprays," in SAE Technical Paper, 2002.

[5] T. Tomonaga, K. Murai, T. Takano, and H. Sami, "A Study on Combustion Behavior of a Diesel Fuel Spray Impinging on a Wall," in SAE Technical Paper, 1996.

[6] J. E. Dec and D. R. Tree, "Diffusion-Flame / Wall Interactions in a Heavy-Duty DI Diesel Engine," in $S A E$ Technical Paper, 2001.

[7] R. Payri, J. Gimeno, M. Bardi, and A. H. Plazas, "Study liquid length penetration results obtained with a direct acting piezo electric injector," Appl. Energy, vol. 106, no. JUNE, pp. 152-162, 2013.

[8] M. Bardi, R. Payri, L.-M. Malbec, G. Bruneaux, L. M. Pickett, J. Manin, T. Bazyn, and C. L. Genzale, "Engine Combustion Network: Comparison of Spray Development, Vaporization, and Combustion in Different Combustion Vessels," At. Sprays, vol. 22, no. 10, pp. 807-842, 2012.

[9] J. Gimeno, G. Bracho, P. Martí-Aldaraví, and J. E. Peraza, "Experimental study of the injection conditions influence over n-dodecane and diesel sprays with two ECN single-hole nozzles. Part I: Inert atmosphere," Energy Convers. Manag., vol. 126, pp. 1146-1156, 2016.

[10] K. Su and S. C. Yao, "Numerical studies of sprays impacting normally on an infinite plate," in $X V$ Congresso Brassileiro de Engenharia Mecânica, 1999.

[11] D. F. Durão, A. L. N. Moreira, and M. R. O. Panão, "The effect of a cross-flow on secondary atomization in multipoint fuel injection systems," 13th Int Symp Appl. Laser Tech. to Fluid Mech., no. January, pp. 112, 2006.

[12] J. Senda, M. Ohnishi, T. Takahashi, H. Fujimoto, A. Utsunomiya, and M. Wakatabe, "Measurement and Modeling on Wall Wetted Fuel Film Profile and Mixture Preparation in Intake Port of SI Engine," in SAE Technical Paper, 1999.

[13] U. Meingast, M. Staudt, L. Reichelt, and U. Renz, "Analysis of Spray / Wall Interaction Under Diesel Engine Conditions," SAE Tech. Pap. 2000-01-0272, no. 724, pp. 1-15, 2000.

[14] F. Birkhold, U. Meingast, P. Wassermann, and O. Deutschmann, "Analysis of the Injection of Urea-WaterSolution for Automotive SCR DeNOx-Systems: Modeling of Two-Phase Flow and Spray/Wall-Interaction," in SAE Technical Paper, 2006.

[15] ECN, "Engine Combustion Network," 2010. [Online]. Available: www.sandia.gov/ecn/.

[16] L. M. Pickett, C. L. Genzale, G. Bruneaux, L.-M. Malbec, and C. Christiansen, "Comparison of diesel spray combustion in different high-temperature, high-pressure facilities," SAE Int. J. Engines, vol. 3, pp. 156-181, 2010.

[17] R. Payri, J. M. Garcia-Oliver, M. Bardi, and J. Manin, "Fuel temperature influence on diesel sprays in inert and reacting conditions," Appl. Therm. Eng., vol. 35, no. March, pp. 185-195, Mar. 2012.

[18] R. Payri, J. Gimeno, J. Cuisano, and J. Arco, "Hydraulic characterization of diesel engine single-hole injectors," Fuel, vol. 180, pp. 357-366, 2016.

[19] R. Payri, F. J. Salvador, J. Gimeno, and J. E. Peraza, "Experimental study of the injection conditions influence over n-dodecane and diesel sprays with two ECN single-hole nozzles. Part II: Reactive atmosphere," Energy Convers. Manag., vol. 126, pp. 1157-1167, 2016.

[20] F. R. Westlye, M. Battistoni, S. A. Skeen, J. Manin, L. M. Pickett, and A. Ivarsson, "Penetration and combustion characterization of cavitating and non-cavitating fuel injectors under diesel engine conditions," SAE Tech. Pap. 2016-01-0860, p. 15, 2016. 